\title{
Cross Border Interference between IMT-Advanced and DVB-T in the Digital Dividend Band
}

\author{
Walid A Hassan ${ }^{1}$, Han-Shin Jo ${ }^{2}$, Zaid A Shamsan ${ }^{3,4}$ and Tharek A Rahman ${ }^{1}$ \\ ${ }^{1,4}$ Wireless Communication Center, Faculty of Electrical Engineering, \\ Universiti Teknologi Malaysia, Malaysia \\ ${ }^{2}$ Dept. of Electronics \& Control Engineering \\ Hanbat National University, Korea \\ ${ }^{3}$ Communications and Computer Department, Faculty of Engineering and \\ Information Technology, Taiz University, Taiz. \\ ${ }^{4}$ Deanship of Academic Research, Al-Imam Mohammad ibn Saud Islamic University, \\ Riyadh, Saudi Arabia \\ walid.a.hassan@gmail.com,hsjo@hanbat.ac.kr,Shamsan22@gmail.com, \\ tharek@fke.utm.my
}

\begin{abstract}
The 470-862 $\mathrm{MHz}$ band has recently incurred two major spectrum reallocations: the introduction of digital broadcasting (DB) and the allocation of the 790-862 $\mathrm{MHz}$ sub-band as a co-primary base for mobile services. While some countries have accomplished full digital switchover (DSO) and implemented DB as their platform for TV broadcasting, others are still in the trial phase. Until 2015, this sub-band will be usable for either broadcasting or mobile service; lack of coordination between neighboring countries could thus result in co-channel interference. Using a Monte Carlo method, we evaluated the minimum separation distance (MSD) and carrier frequency separation necessary to achieve compatibility. Digital video broadcasting-terrestrial (DVB-T) systems can be protected from international mobile telecommunications-advanced (IMT-A) systems using a carrier frequency separation of 17 $M H z$. Although IMT-A systems are not protected from DVB-T in this sharing scenario, coexistence between adjacent channels is ensured without recourse to interference mitigation by use of a carrier frequency of at least $15 \mathrm{MHz}$.
\end{abstract}

Keywords: Compatibility Analysis; Spectrum Sharing; Monte Carlo Methodology, Interference, Coexistence, Cross Border Interference

\section{Introduction}

In the latest Regional Radiocommunications Conference in 2006 (RRC-06), the International Telecommunication Union (ITU) set deployment requirements for digital video broadcasting-terrestrial (DVB-T) service in Bands IV and V (i.e., 470-862 MHz) [1]. In 2007, Resolution 794 of the World Radio Conference (WRC-07) allocated this band as a coprimary basis for mobile and broadcasting services starting in 2015 and indicated that studies on sharing between the two services should be conducted [2].

In 2008, the European Commission directed the European Conference of Postal and Telecommunication (CEPT) to set the requirements for harmonizing spectrums between European Union countries; included in this mandate was the stated need to study technical conditions within the $790-862 \mathrm{MHz}$ band. A detailed study was carried out [3] to identify 
frequency channel arrangements within this band for mobile services. The recommendations of the study were adopted in 2009 as the response of the European Union to the ITU request at WRC-07 to conduct sharing studies between mobile and broadcasting services [4]

Based on the facts that a) the ITU has set aside the $470-862 \mathrm{MHz}$ band for terrestrial digital broadcasting and b) future IMT-A mobile services will operate in the 791-862 MHz band [4], frequency sharing between the two systems (and consequently, performance degradation) are inevitable. The goal of this paper is to quantify the possibilities for compatibility between the two services and to propose a practical guideline for guaranteeing efficient spectrum usage and reliable service.

\section{Related Work}

Our paper is inspired by the limitations of recent compatibility studies [5-9]. Although the radio interference effects of Long Term evolution-Advanced (LTE-A) base station (BS) and user equipment (UE) on DVB-T receivers were examined in [5], reverse interference was not investigated. In [6], the possibility of co-existence of IMT-A BS and DVB-T BS in the 790$862 \mathrm{MHz}$ band by use of sensitive and non-sensitive spectrum emission masks (SEMs) on DVB-T transmitters was analyzed. In [7], interference from DVB-T BS to IMT-A BS was investigated using minimum coupling loss methodology over three co-existence scenarios: co-channel, adjacent channel, and zero guard band. In neither of these studies, however, was the receiver blocking response assessed as a part of the interference effect, and other interference scenarios, such as DVB-T BS to IMT-A UE and IMT-A UE to DVB-T subscriber station (SS), were excluded. In [8], the required guard band (GB) and minimum separation distance (MSD) between evolved-UMTS terrestrial radio access (E-UTRA) and digital broadcasting (DB) services were assessed for co- and adjacent-channel interference scenarios. However, the results were inexact, since the study did not utilize an E-UTRAspecified SEM [10] and system specifications were not provided, making testing (or implementation) of the results impossible. Finally, in [9] an inter-system performance measurement was conducted by developing a methodology based on a previous technical report [11]. This study revolved around co-channel interference, and adjacent channel interference was only suggested for future work; furthermore, only urban deployment was assessed.

In order to obtain reliable co-existence and compatibility results, a more general and exact approach is clearly desirable. The effects and parameters that should be studied include transmitter interference leakage, receiver imperfection, and exact system specification, all of which should be assessed under all potential interference scenarios. In particular, for the study described in this paper, we quantify the possibility of compatibility under various interference scenarios in both rural and urban environments: (i) DVB-T BS to IMT-A BS and UE, (ii) IMT-A BS to DVB-T SS, and (iii) IMT-A UE to DVB-T SS. By adopting Monte Carlo (MC) methodology to conduct these assessments, we are able to provide more realistic compatibility results by randomly distributing users within the service coverage.

\section{System Parameters}

In this study, we assess the parameters of LTE-A parameters (shown in Table 1), as this is one of the candidate technologies for IMT-A systems [12-13] . 
Table 1. LTE-A [12-13] parameters in rural and urban area deployment

\begin{tabular}{|c|c|c|c|c|}
\hline & \multicolumn{2}{|c|}{ LTE-A (BS) } & \multicolumn{2}{|c|}{ LTE-A (UE) } \\
\hline Parameter & Rural & Urban & Rural & Urban \\
\hline $\begin{array}{l}\text { Transmitted power } \\
(\mathrm{dBm})\end{array}$ & $\begin{array}{r}46 \leq 5 \mathrm{MHz} \\
43 \geq 5 \mathrm{MHz}\end{array}$ & 23 & \multicolumn{2}{|c|}{24} \\
\hline Bandwidth (MHz) & \multicolumn{2}{|c|}{20} & & \\
\hline Height (m) & 30 & 23.5 & \multicolumn{2}{|c|}{1.5} \\
\hline Gain $(\mathrm{dBi})$ & \multicolumn{2}{|c|}{15} & & \\
\hline Noise figure $(\mathrm{dB})$ & \multicolumn{2}{|c|}{5} & \multicolumn{2}{|c|}{9} \\
\hline Coverage $(\mathrm{km})$ & 4.3 & 0.5 & \multicolumn{2}{|c|}{$\begin{array}{ll}--- \\
\end{array}$} \\
\hline Antenna & \multicolumn{2}{|c|}{ Tri Sector [14] } & \multicolumn{2}{|c|}{ Omni } \\
\hline $\mathrm{ACS}(\mathrm{dB})$ & \multicolumn{4}{|c|}{$27($ for $\mathrm{BW}=20 \mathrm{MHz})$} \\
\hline Thermal noise $(\mathrm{dBm})$ & \multicolumn{2}{|c|}{$-95.98(20 \mathrm{MHz})$} & \multicolumn{2}{|c|}{$-91.98(20 \mathrm{MHz})$} \\
\hline $\begin{array}{l}\text { Interference threshold } \\
\qquad(\mathrm{dBm})\end{array}$ & \multicolumn{2}{|c|}{$-101.98(20 \mathrm{MHz})$} & \multicolumn{2}{|c|}{$-97.98(20 \mathrm{MHz})$} \\
\hline Sensitivity (dBm) & \multicolumn{2}{|c|}{-90.98} & \multicolumn{2}{|c|}{-86.98} \\
\hline Propagation model & \multicolumn{4}{|c|}{ Extended Hata [15] } \\
\hline Cell layout & \multicolumn{2}{|c|}{$\begin{array}{c}\text { Wrap around 57tri sector cells, } \\
\text { uncoordinated }\end{array}$} & \multicolumn{2}{|c|}{----} \\
\hline Scheduling algorithm & \multicolumn{4}{|c|}{ Round Robn } \\
\hline Number of users & \multicolumn{2}{|c|}{----} & 20 & 50 \\
\hline SEM & \multicolumn{2}{|c|}{ [12] (when Tx) } & \multicolumn{2}{|c|}{ [13] (when Tx) } \\
\hline $\begin{array}{l}\text { Receiver blocking } \\
\text { attenuation mode }\end{array}$ & \multicolumn{4}{|c|}{ Sensitivity mode } \\
\hline $\begin{array}{l}\text { Minimum coupling Loss } \\
\text { (inter-system) [14] }\end{array}$ & 80 & 70 & 80 & 90 \\
\hline
\end{tabular}

Here, DVB-T is used for the DB system [1]. All of the broadcasting deployment requirements, specifications, and protections used for this and other services assessed here were previously addressed in [1]. Table 1 contains LTE-A and DVB-T parameters for rural and urban environments.

Table 2. DVB-T [1] parameters in rural and urban area deployment

\begin{tabular}{|c|c|c|c|c|}
\hline & \multicolumn{2}{|c|}{ DVB-T (BS) } & \multicolumn{2}{|c|}{ DVB-T (SS) } \\
\hline Parameter & Rural & Urban & Rural & Urban \\
\hline $\begin{array}{l}\text { Transmitted power } \\
(\mathrm{dBm})\end{array}$ & 74.6 & 63.6 & \multicolumn{2}{|c|}{---- } \\
\hline Bandwidth (MHz) & \multicolumn{4}{|c|}{8} \\
\hline Height (m) & 200 & 100 & \multicolumn{2}{|c|}{10} \\
\hline Gain $(\mathrm{dBi})$ & \multicolumn{2}{|c|}{0} & \multicolumn{2}{|c|}{14.15} \\
\hline Noise figure $(\mathrm{dB})$ & \multicolumn{2}{|c|}{----} & \multicolumn{2}{|c|}{7} \\
\hline Coverage radius $(\mathrm{km})$ & 51.76 & 17 & \multicolumn{2}{|c|}{---- } \\
\hline Antenna & \multicolumn{2}{|c|}{ Omni } & \multicolumn{2}{|c|}{ ITU-R BT.419-3 [16] } \\
\hline Thermal noise $(\mathrm{dBm})$ & \multicolumn{2}{|c|}{----} & \multicolumn{2}{|c|}{-98} \\
\hline Sensitivity $(\mathrm{dBm})$ & \multicolumn{2}{|c|}{----} & -78 & -82 \\
\hline Propagation model & \multicolumn{4}{|c|}{ Extended Hata Model } \\
\hline Network Type & RN1 & RN3 & & \\
\hline
\end{tabular}




\begin{tabular}{|c|c|c|c|c|}
\hline $\mathrm{C} / \mathrm{N}(\mathrm{dB})$ & 21 & 17 & \multicolumn{2}{|c|}{----} \\
\hline $\mathrm{C} / \mathrm{I}(\mathrm{dB})$ & 27 & -30 & 23 & -30 \\
\hline $\begin{array}{l}\text { Reception } \\
\text { configuration }\end{array}$ & \multicolumn{2}{|c|}{---} & \multicolumn{2}{|c|}{ RPC 1} \\
\hline SEM & \multicolumn{2}{|c|}{ GE06 [1] } & \multicolumn{2}{|c|}{---} \\
\hline $\begin{array}{l}\text { Receiver blocking } \\
\text { attenuation mode }\end{array}$ & \multicolumn{2}{|c|}{---- } & \multicolumn{2}{|c|}{ PR } \\
\hline $\begin{array}{l}\text { Allowed Maximum } \\
\text { interfering signal } \\
(\mathrm{dBm})\end{array}$ & \multicolumn{2}{|c|}{----} & \multicolumn{2}{|c|}{-104} \\
\hline Receiver type & \multicolumn{2}{|c|}{----} & \multicolumn{2}{|c|}{ Silicon USB[17] } \\
\hline
\end{tabular}

\section{Compatibility Method}

In the MC simulation used for this study, a series of trials was repeated using a set of varied, user-defined parameters in order to calculate a protection criterion, such as the carrierto-interfering $(C / I)$ or the interfering-to-noise $(I / N)$ ratio, for each trial. After a sufficient number of trials (i.e., 10,000 snapshots), the probability of interference $P_{\text {int }}$ can be calculated as follows [15]:

$$
P_{\text {int }}=1-P_{\text {non_int }} \text {, }
$$

where $P_{\text {non_int }}$ is the probability of non-interference of the victim receiver when $\left(\mathrm{D}_{\mathrm{E}} / \mathrm{I}_{\mathrm{E}}>\mathrm{C} / \mathrm{I}\right)$. Here, $D_{E}$ is the desired signal power and $I_{E}$ is the interference power.

In each trial (or snapshot), the victim receiver obtains a desired $D_{E}(\mathrm{dBm})$ and an interference $I_{E}(\mathrm{dBm})$ signal. The desired signal, $D_{E}$, is given by

$$
D_{E}=P_{w t}+G_{w t}+G_{v r}-L_{p}
$$

where $P_{w t}$ is the transmitting power of the desired transmitter $(\mathrm{dBm}), G_{w t}$ is the antenna gain of the desired transmitter $(\mathrm{dBi}), G_{v r}$ is the gain of the victim receiver $(\mathrm{dBi}), L_{p}$ is path loss $(\mathrm{dBm})$ based on an extended Hata model, $P_{i t}$ is the power of interference $(\mathrm{dBm})$, and $G_{i t}$ is the gain of the interfering antenna $(\mathrm{dBi})$.

The interference signal IE is composed of two sources, unwanted emission $\left(I_{E_{-} \text {unwanted }}\right)$ and receiver imperfection $\left(I_{E_{-} \text {blocking }}\right)$ :

$$
I_{E}=I_{E_{\text {unwanted }}}+I_{E_{\text {Blocking }}},
$$

The total interference over the $n$ trials owing to unwanted transmitter emission is then given as follows [15]:

$$
I_{E_{-} \text {unwamted }}(\mathrm{dBm})=10 \log _{10}\left\{\sum_{i=1}^{n} 10^{\frac{I_{E_{-} \text {unwanted } i}}{10}}\right\} \text {, }
$$


For the $i$-th trial, $I_{E \_ \text {unwanted }}$ is given by

$$
I_{E_{-} \text {unwanted_i }}=i T_{\text {emission }}\left(f_{i t}, f_{v r}\right)+G_{i t}+G_{v r}-L_{p},
$$

where $G_{i t}$ is the antenna gain of the interfering system $(\mathrm{dBi})$ and $i T_{\text {emission }}\left(f_{i t} f_{v r}\right)$ is the emission leakage from an interfering transmitter operating at a frequency offset of $f_{i t}$, into the victim receiver, which in turn operates at frequency $f v r$.

The $i T$ emission $\left(f_{i t}, f_{v r}\right)$ factor is a function of operating frequency offset $(\mathrm{MHz})$, unwanted emission power, and the reference bandwidth (MHz):

$$
\begin{aligned}
& i T_{\text {emission }}\left(f_{i t}, f_{v r}\right)=P_{i t}+\text { emission }_{\text {unwanted }}\left(f_{i t}, f_{v r}\right), \\
& \text { emission }_{\text {unwanted }}(n)\left(f_{i t}, f_{v r}\right)=10 \log _{10}\left\{\int_{a}^{b} P_{\text {unwanted }}(\Delta f) d \Delta f\right\},
\end{aligned}
$$

where $P_{i t}$ is the transmission power of the interfering system $(\mathrm{dBm}), \Delta f=f_{i t}-f_{v r}(\mathrm{MHz})$, and emission $_{\text {unwanted }}\left(f_{i t}, f_{v r}\right)(\mathrm{dBm})$ is the total power falling into in the victim receiver filter as an integrated function of the unwanted power $P_{\text {unwanted }}(\mathrm{dBm})$ over the frequency range between $a=f_{v r}-f_{i t}-\left(b_{v r} / 2\right)$ and $b=f_{v r}+f_{i t}-\left(b_{v r} / 2\right)$, where $b_{v r}$ is the victim receiver bandwidth.

The interference owing to victim receiver blocking over $n$ trials can be given by

$$
\text { emission }_{\text {unwanted }}\left(f_{i t}, f_{v r}\right)=10 \log _{10}\left\{\int_{a}^{b} P_{\text {unwanted }}(\Delta f) d \Delta f\right\}
$$

For the $i$-th trial, the interference blocking can be given as a function of frequency:

$$
I_{E_{-} \text {Blocking }}=P_{i t}+G_{i t}+G_{v r}-L p-a v r(\Delta f) \text {, }
$$

where $\operatorname{avr}(\Delta f)(\mathrm{dBm})$ is the blocking attenuation of the victim receiver, which can be calculated using one of two modes, sensitivity mode or PR mode, chosen based on receiver type. In the simulation used here, PR mode was chosen for the broadcasting receiver, while sensitivity mode was chosen to calculate receiver-blocking attenuation in the mobile receiver, as is shown in Tables 1 and 2. Using sensitivity mode, the blocking attenuation can be given as follows [15]:

$$
\operatorname{avr}(\Delta f)=I_{\max }+C /(N+1)+\operatorname{Sen}_{v r}
$$


where $I_{\max }(\mathrm{dBm})$ is the maximum allowed interference and $\operatorname{Sen}_{v r}(\mathrm{dBm})$ is the sensitivity level of the victim receiver.

For PR mode, we use

$$
\operatorname{avr}(\Delta f)=3+C /(N+1)+\operatorname{Block}_{a t t}\left(f_{i t}-f_{v r}\right)
$$

where $I(\mathrm{dBm})$ is the level of interference and $N(\mathrm{dBm})$ is the noise floor level of the receiver. Both of these factors are functions of the frequency difference, $\Delta f$

\section{Interference Scenario}

Figure 1 illustrates frequency sharing between LTE-A and DVB-T systems in both uplink (UL) and downlink (DL) communication modes. This condition is relevant to the situation that will apply under all administrations that agree to Geneva Agreement 2006 (GE-06), under which LTE-A is to be used as the IMT-A system. Here, DVB-T channels 61 to 63 and 66 to 68 overlap totally or partially with the LTE-A DL channel, causing co-channel interference, while channels $(60,64)$ and $(65,69)$ produce adjacent channel interference. The LTE-A UL/DL channels are assumed to have a $20 \mathrm{MHz}$ bandwidth. This scenario can occur if one country (such as Singapore) decides to deploy a mobile system in the 790-862 MHz band, while its neighbor (e.g., Malaysia) is still using DB.

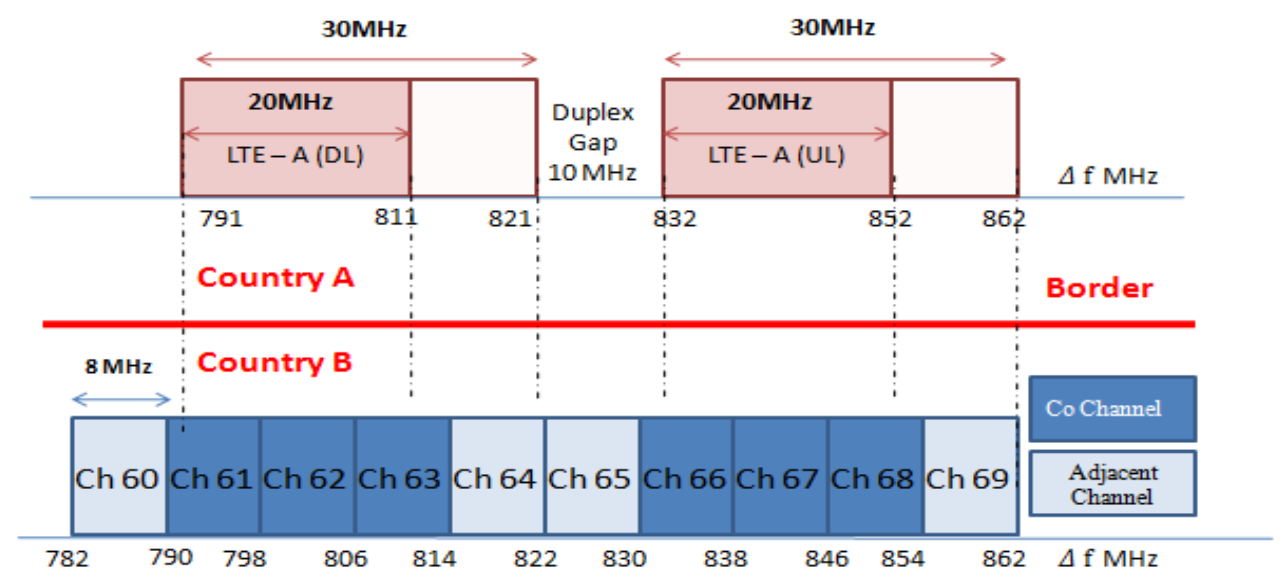

Figure 1. Sharing of the $790-862 \mathrm{MHz}$ band between LTE-A (UL/DL) and DVB-T

We consider here four interference scenarios: (i) LTE-A BS interfering with DVB-T SS, (ii) LTE-A UE interfering with DVB-T SS, (iii) DVB-T interfering with LTE-A BS, and (iv) DVB-T BS interfering with LTE-A UE. In each scenario, the systems are assumed to be deployed in both rural and urban environments.

\section{Results and Discussion}

Tables 3 and 4 show the minimum separation distances $M S D(\mathrm{~km})$ required for coexistence in the four interference scenarios. These separation distances are functions of frequency offset $\triangle f(\mathrm{MHz}) ; G B(\mathrm{MHz})$ is the guard band, while $C h$ is the channel number. The red highlighted results in the tables show the worst cases, while the yellow highlighted results represent cases 
where co-existence can be achieved. In any sharing study between mobile and broadcasting services, channel frequency assignments must be taken into consideration in order to obtain realistic results.

Table 3. Minimum separation distance between the LTE-A (BS, UE) and the DVB-T SS

\begin{tabular}{|c|c|c|c|c|c|c|c|c|c|c|}
\hline & \multicolumn{10}{|c|}{ [ 1st interference scenario ] LTE-A (BS) $(D L) \rightarrow D V B-T(T S)$} \\
\hline & \multicolumn{5}{|c|}{ Rural } & \multicolumn{5}{|c|}{ Urban } \\
\hline & \multicolumn{3}{|c|}{$\begin{array}{c}C o-C h \\
P R=27 d B\end{array}$} & \multicolumn{2}{|c|}{$\begin{array}{c}A d j-C h \\
P R=-30 d B\end{array}$} & \multicolumn{3}{|c|}{$\begin{array}{c}\text { Co-Ch } \\
P R=17 \mathrm{~dB}\end{array}$} & \multicolumn{2}{|c|}{$\begin{array}{c}\text { Adj-Ch } \\
P R=-30 \mathrm{~dB}\end{array}$} \\
\hline Ch & 61 & 62 & 63 & 60 & 64 & 61 & 62 & 63 & 60 & 64 \\
\hline $\begin{array}{l}M S D \\
(\mathbf{k m})\end{array}$ & 215 & 220 & 210 & \multicolumn{2}{|c|}{0} & 35 & 40 & 33 & \multicolumn{2}{|c|}{0} \\
\hline $\begin{array}{l}\Delta f \\
(\mathrm{MHz})\end{array}$ & 7 & 1 & 9 & 15 & 17 & 7 & 1 & 9 & 15 & 17 \\
\hline $\begin{array}{l}G B \\
(\mathrm{MHz})\end{array}$ & \multicolumn{3}{|c|}{0} & 1 & 3 & \multicolumn{3}{|c|}{0} & 1 & 3 \\
\hline \multicolumn{11}{|c|}{ [ 2nd interference scenario] LTE-A (UE) (UL) $\rightarrow D V B-T(S S)$} \\
\hline Ch & \multicolumn{2}{|c|}{$66 / 68$} & 67 & \multicolumn{2}{|c|}{$65 / 69$} & \multicolumn{2}{|c|}{$66 / 68$} & 67 & \multicolumn{2}{|c|}{$65 / 69$} \\
\hline $\begin{array}{l}M S D \\
(\mathbf{k m})\end{array}$ & \multicolumn{2}{|c|}{1.5} & 1.6 & \multicolumn{2}{|c|}{0} & \multicolumn{2}{|c|}{0.6} & 0.4 & \multicolumn{2}{|c|}{0.1} \\
\hline $\begin{array}{l}\Delta f \\
(\mathrm{MHz})\end{array}$ & \multicolumn{2}{|c|}{8} & 0 & \multicolumn{2}{|c|}{16} & \multicolumn{2}{|c|}{8} & 0 & \multicolumn{2}{|c|}{16} \\
\hline $\begin{array}{l}\text { GB } \\
(\mathrm{MHz})\end{array}$ & \multicolumn{3}{|c|}{0} & \multicolumn{2}{|c|}{2} & \multicolumn{3}{|c|}{0} & \multicolumn{2}{|c|}{2} \\
\hline
\end{tabular}

In the first interference scenario, co-existence can be achieved for adjacent channels 60 and 64; i.e., $G B$ is 1 and $3 \mathrm{MHz}$, respectively, for each channel in urban deployment. In the second interference scenario, co-existence can be achieved for adjacent channels 65 and 69, as $G B=2 \mathrm{MHz}$ in rural deployment. As a minimum separation distance between systems is quite hard to maintain, owing to the random deployment of UEs, this scenario is considered crucial for determining the interference effect of an LTE-A on a DVB-T system. For example, in an urban environment the two systems should be at least $100 \mathrm{~m}$ apart when using adjacent channels 65 or 69 , while an $M S D$ of 600,400 , and $600 \mathrm{~m}$ is required for co-channels 66,67 , and 68 , respectively.

In the fourth interference scenario, coexistence in rural deployment can only be achieved by sharing the adjacent channels of $65 / 69$ (i.e., $G B=2$ ), and in the third scenario, coexistence cannot be achieved for both co-channel and adjacent channel sharing in rural and urban environments, as the distances required to protect the victim service are very large compared to those in the other sharing scenarios, owing to the high transmitted power levels of the DVB-T BS. 


\section{Table 4. Minimum separation distance between the DVB-T BS and the LTE-A} (BS, UE)

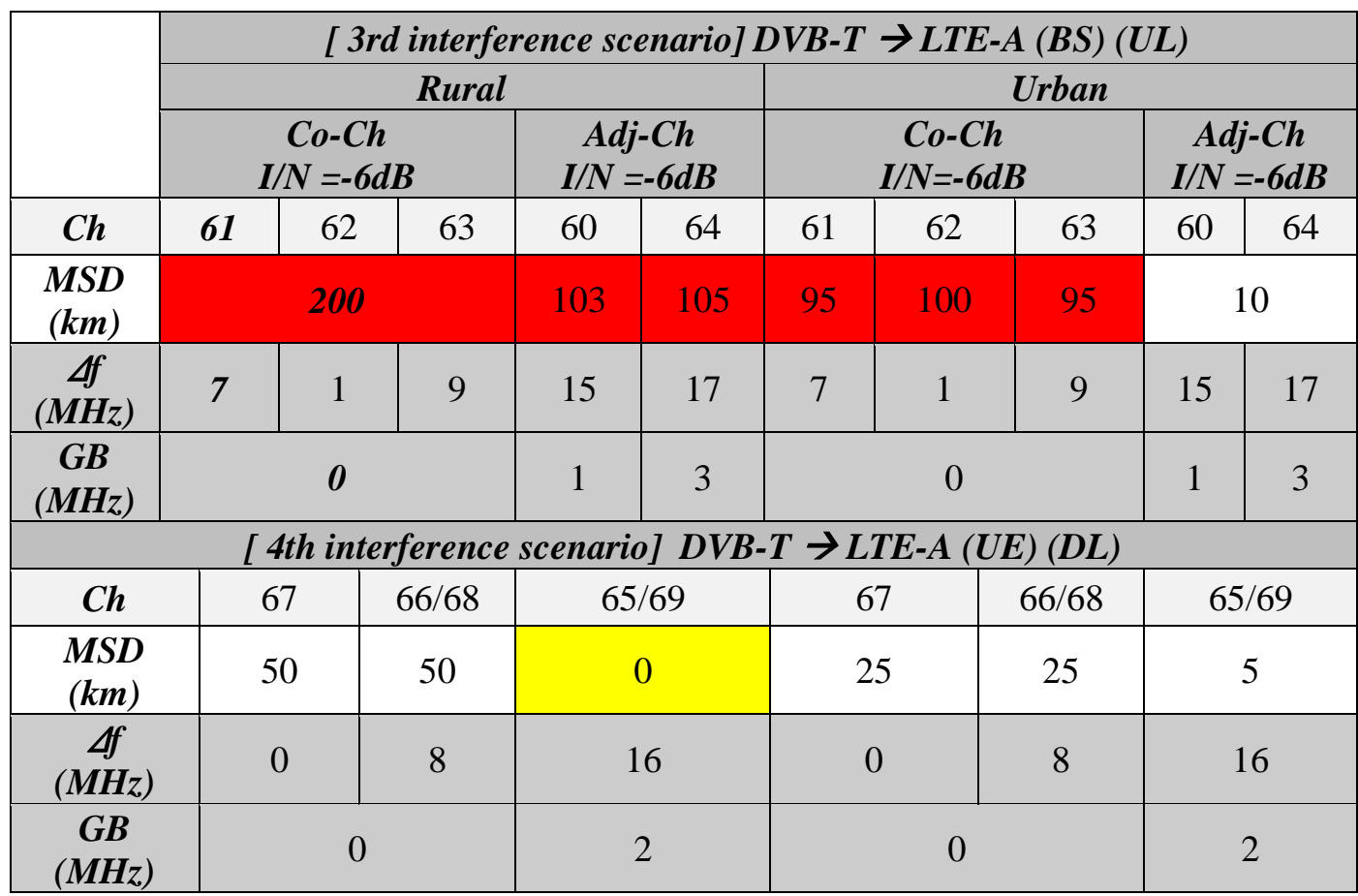

\section{Conclusion}

On the whole, the simulation results discussed in this paper show that coexistence between the two services described here is impossible in co-channels as well as, in some situations, adjacent channels. These results differ from those of previous studies [5-8], in which it was found that the two systems can coexist under all adjacent channel sharing scenarios. Our results should serve as an alert to the possible consequences of international cross-border interference in the 790-862 MHz band.

Our results can also aid in the successful deployment of IMT-A and DVB-T systems within the 790-862 MHz band by ensuring that adequate distance is maintained and a guard band is used. In other sharing scenarios, however, interference mitigation will still be required.

\section{Acknowledgements}

This work was supported by the Research Management Centre (RMC), Universiti Teknologi Malaysia (UTM) under the Post Doctoral Fellowship scheme.

\section{References}

[1] RRC-06, "Final Acts of the Regional Radiocommunication Conference for Planning of the Digital Terrestrial Broadcasting Service in Parts of Regions 1 and 3, in the Frequency Bands 174-230 MHz and 470-862 MHz (RRC-06)", ITU Geneva, (2006), http://www.ucc.co.ug/spectrum/geO6digitalFinalActs.pdf.

[2] Resolution 794 (WRC-07), "Studies on the use of the band 790-862 MHz by mobile applications and by other services", International Telecommunication Union (ITU), (2007), http://www.itu.int. 
[3] CEPT Report 30, "The identification of common and minimal (least restrictive) technical conditions for 790$862 \mathrm{MHz}$ for the digital dividend in the European Union", European Conference of Postal and Telecommunications (CEPT), (2009), http://www.erodocdb.dk/doks/doccategoryECC.aspx?doccatid=16.

[4] V. P. Kalogirou, E. D. Nanou, N. C. Capsalis, T. N. Velivasaki and C. N. Capsalis, "Compatibility of DVB-T services and IMT-2000 compliant mobile telecommunications in the UHF band of 470-862 MHz", 9th International Conference on Telecommunication in Modern Satellite, Cable, and Broadcasting Services, (2009), TELSIKS '09, October 7-9, Serbia, IEEE, pp. 247-254.

[5] W. Wang, B. Wang, Z. Lv, W. Huang and Y. Zhang, "Analysis of interference from digital Terrestrial Television Broadcast to LTE TDD in Digital Dividend spectrum", 2nd IEEE International Conference on Network Infrastructure and Digital Content, (2010) September 24-26, Beijing, China IEEE, pp. 692-697.

[6] Z. A. Shamsan, T. A. Rahman and M. R. Kamarudin, "Coexistence and Sharing between IMT-Advanced and DVB-T Services at 790-862 MHz", Proceedings of the 9th WSEAS international conference on Telecommunications and informatics. Catania, Sicily, Italy, WSEAS, (2010), pp. 85-90.

[7] Z. A. Shamsan and T. A. Rahman, "T-DVB Services Coexistence with IMT-advanced Service", Progress In Electromagnetics Research Symposium Proceedings, (2009), pp. 405-409.

[8] D.Setiawan, D. Gunawan and D. Sirat, "Interference Analysis of Guard Band and Geographical Separation between DVB-T and E-UTRA in Digital Dividend UHF Band", International Conference on Instrumentation, Communication, Information Technology, and Biomedical Engineering, (2009), pp. 254-259.

[9] A. Guidotti, D. Guiducci, M. Barbiroli, C. Carciofi, P. Grazioso and G. Riva, "Coexistence and Mutual Interference between Mobile and Broadcasting Systems", IEEE 73rd Vehicular Technology Conference (VTC Spring), (2011) May 15-18, Budapest, IEEE, pp. 1-5.

[10] 3GPP TS 36.101 v10.2.0, "Technical Specification Group Radio Access Network;Base Station (BS) radio transmission and reception (Release 10)", (2010), www.3gpp.org.

[11] M. Barbiroli, et al., "Coexistence and mutual interference between mobile radio and broadcast systems", European Cooperation in the field of scientific and technical research Braunschweig, Germany, (2009), http://www.fub.it/files/TD(09)709.pdf.

[12] 3GPP TS 36.101 V10.4.0, "Technical Specification Group Radio Access Network;Base Station (BS) radio transmission and reception (Release 10)", 3GPP, (2010), www.3gpp.org.

[13] 3GPP TS 36.104 V10.4.0, "Technical Specification Group Radio Access Network;User Equipment (UE) radio transmission and reception (Release 10)", (2010), www.3gpp.org.

[14] TR 36.942 V10.2.0 (2010-12), "Technical Specification Group Radio Access Network; Evolved Universal Terrestrial Radio Access (E-UTRA); Radio Frequency (RF) system scenarios (Release 10)", 3GPP, (2010), www.3gpp.org.

[15] ERC 68, "Monte-Carlo Simulation methdology for the use in the shaing and compatibilty studies between different radio service or systems", http://www.erodocdb.dk/docs/doc98/official/pdf/Rep068.pdf.

[16] ITU-R BT.419-3, "Directivity and polarization discrimination of antennas in the reception of television broadcasting ITU", (1992), www.itu.int/rec/R-REC-BT.419/en.

[17] ECC148, "Measurements on the performance of the DVB-T receivers in the presence of the interference from the mobile service (especially from LTE)", Marseille. E.a. CEPT, (2010), www.erodocdb.dk/docs/doc98/official/pdf/ECCRep148.pdf.

\section{Authors}

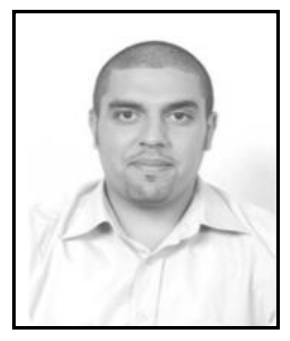

Dr. Walid A Hassan (Iraqi) is a Post Doctoral Research Fellow, Wireless Communication Centre (WCC), Faculty of Electrical Engineering (FKE), Universiti Teknologi Malaysia (UTM). He obtained his PhD from University Technology Malaysia in 2012. His Master was in the faculty of engineering, University Technology Malaysia in 2011. His BSc was from Garyounis University Faculty of electrical and electronic engineering (telecommunication major) Benghazi, Libya. Dr. Walid had involved in several project with the Malaysian Communication and Multimedia commission (MCMC) from 2009 till 2012. His research interest includes spectrum sharing method, co-existence and compatibility between wireless communication, cognitive radio spectrum sharing methods. 


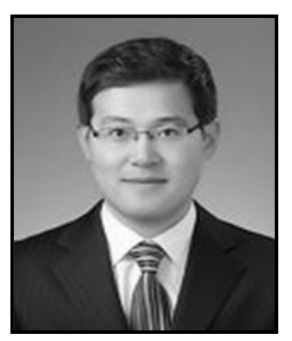

Dr. Han-Shin Jo is an Assistant Professor with the Department of Electronics and Control Engineering, Hanbat National University in Korea. He was a Postdoctoral Research Fellow in Wireless Networking and Communications Group, the Department of Electrical and Computer Engineering, the University of Texas at Austin from 2009-11. Dr. Jo developed LTE systems in Samsung Electronics in 2011-12. He received the B.S., M.S., and Ph.D. degrees in Electrical and Electronics Engineering from Yonsei University Seoul, Korea, in 2001, 2004, and 2009, respectively. He received 2011 ETRI Journal Award. His research interests include Small cells, Heterogeneous network, Wireless ad-hoc network, Stochastic geometry, and Wireless broadband transmission

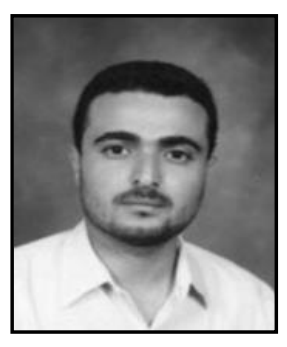

Dr. Zaid A. Shamsan received the B.Eng. (Hons.) degree in electronics and communication engineering from Sudan University of Sciences and Technology, Sudan, in 2002, and the M.Eng. and Ph.D. degrees in Telecommunication and Electrical Engineering from Universiti Teknologi Malaysia (UTM), Malaysia, in 2007 and 2010, respectively.He was a Postdoctoral Research Fellow in Wireless Communication Centre at UTM, from 2010-2012. Dr. Shamsan is currently an Assistant Professor with the Deanship of Scientific Research, Al Imam Mohammad bin Saud Islamic University in Saudi Arabia. Since 2003, he has been an academic staff in the Faculty of Engineering and Information Technology, Taiz University, Yemen. He has published several scientific papers in high impact factor and archival technical journals and conferences. His research interests include orthogonal frequency-division multiplexing technology, interference analysis techniques, wave propagation, mathematical modelling for coexistence analysis in wireless networks, rain fading analysis and mitigation, freespace optics, and optical communication

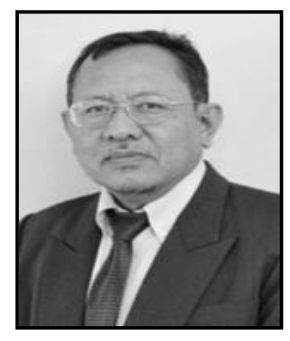

Prof. Dr. Tharek A. Rahman is a Professor at Faculty of Electrical Engineering, Universiti Teknologi Malaysia (UTM). He obtained his BSc. in Electrical \& Electronic Engineering from University of Strathclyde UK in 1979, MSc in Communication Engineering from UMIST Manchester UK and $\mathrm{PhD}$ in Mobile Radio Communication Engineering from University of Bristol, UK in 1988. He is the Director of Wireless Communication Centre (WCC), UTM. His research interests are radio propagation, antenna and RF design and indoors and outdoors wireless communication. $\mathrm{He}$ has also conducted various short courses related to mobile and satellite communication to the Telecommunication Industry and government body since 1990 . He has a teaching experience in the area of mobile radio, wireless communication system and satellite communication. $\mathrm{He}$ has published more than 120 papers related to wireless communication in national/international journal and conference. 